\title{
DÍEZ JORGE, María Elena, De puertas para adentro. La casa en los siglos XV y XVT. Comares, Granada, 2019.
}

\author{
MARTA CRIADO ENGUIX \\ Universidad de Granada
}

Este libro recoge los resultados del proyecto de investigación "De puertas para adentro. Vida y distribución de espacios en la arquitectura doméstica (siglos XV-XVI)" financiado por el Ministerio de Economía y Competitividad con referencia HAR2014-52248-P.

Se trata de una obra coral nutrida de un grupo de investigadores procedentes de diversas disciplinas pero, a su vez, unidos por una línea común: el interior de la vivienda en los siglos XV y XVI. Tan amplio y variado grupo de investigadores requiere de una óptima organización y marco de trabajo.

Como punto de partida, se procede a la definición de los conceptos de hogar, vida cotidiana y domesticidad, a fin de comprobar si son aplicables o no a la época que concierne a su objeto de estudio. De cada capítulo se extraen y diseccionan distintos subapartados que tratan con detalle la temática relacionada con el capítulo principal. Son cuatro los titulares principales en los que se

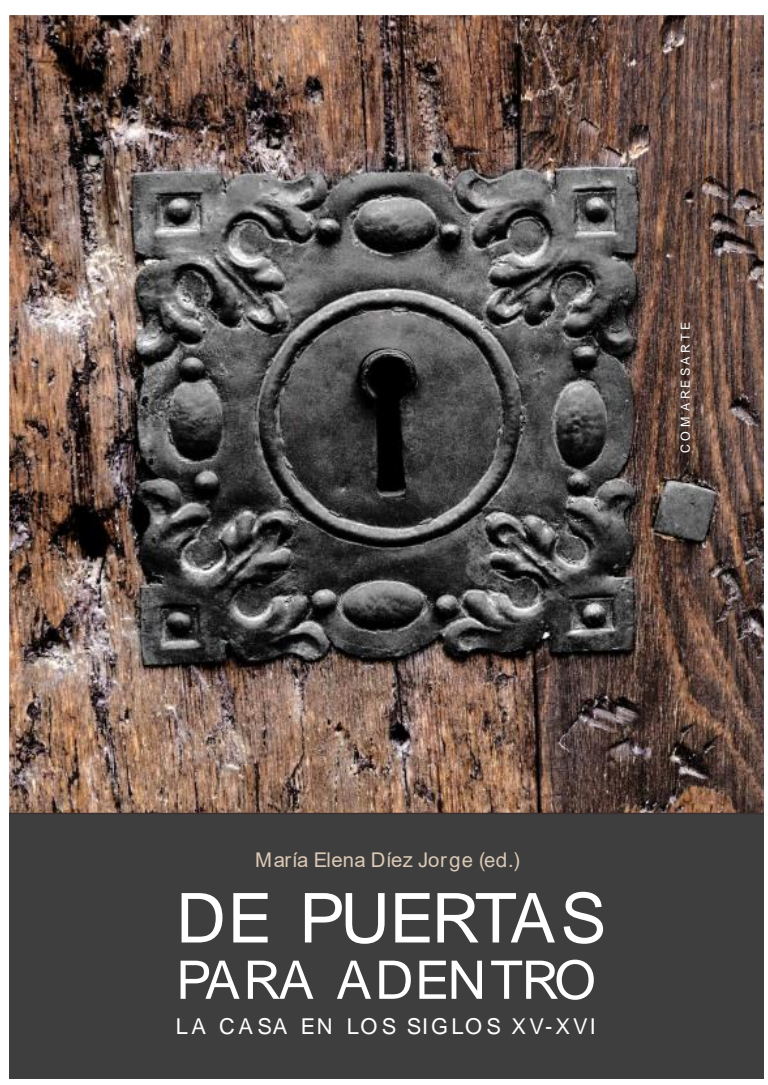
fragmenta la obra: construcción y

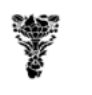

distribución de espacios en la casa de puertas para adentro; los modos de vivir y ocupación de espacios; el mobiliario textil junto a casos concretos y, en último lugar, y con el sugerente título de "al calor del hogar" para centrarse en los ajuares y enseres de casas granadinas, focalizada esta parte en la esfera de las emociones y vivencias que se desarrollaban en el interior de la vivienda. Todos estos aspectos hacen que el libro este cargado de utilidad para todo aquel que se inicie en este camino del interior de la vivienda. Su lectura ofrece al lector 
una idea precisa sobre las herramientas necesarias para su estudio y metodología, así como el uso de diversos marcos de índole teórica, cultural e histórica.

La metodología que se ha empleado para el desarrollo del libro está basada en una ingente labor de archivo así como la investigación de restos arqueológicos y arquitectónicos o el empleo de otros soportes de interés como la cultura material y obras pictóricas de diversos fondos y colecciones. La temática es, sin duda, muy atractiva e innovadora, lo que legitima el interes y la relevancia de esta obra, arrojando en su conjunto una notable coherencia discursiva. Los capitulos se desarrollan con total pulcritud en el afán de recalcar los elementos que configuran el interior de la vivienda: la construcción y distribución de espacios, los modos de vivir y su ocupación, los ajuares domésticos, las labores culinarias, el mundo laboral o las relaciones familiares.

Su estudio se complementa con la incorporación de una amplia variedad territorial: Granada, Jaén, Zaragoza, las casas de la oligarquía malagueña, la fortaleza de Gibraleón, Toledo, Sevilla o incluo con casos de españoles en América como en La Habana (Cuba) o en Tunja (Colombia); ello ofrece una visión global del estado de la cuestión sobre la realidad de la vivienda en estos siglos. Además, cabe reseñar que en la obra no se aplica un método de diferenciación estricto entre el mundo rural y urbano, pues todo forma parte de una realidad de la vivienda en un periodo histórico determinado.

La presente monografía supone un trabajo singular y atractivo sobre una materia compleja y tratada en profundidad. Coincide con el creciente interés suscitado por el estudio de la casa del pasado. Nos hallamos con un enfoque completamente nuevo: el interior de la casa adquiere un valor como hecho de carácter histórico, social y cultural. Por tanto, la obra que el lector tiene a su disposición destaca por el significativo papel que juega la arquitectura doméstica y las vivencias desarrolladas de puertas para adentro.

María Elena Díez, editora principal y experta en este tema, invita al lector, ya desde la presentación del libro, a adentrarse en estos espacios domésticos. Incide de forma constante en la vivienda y su estudio como un espacio físico que funciona como contenedor y organizador de las relaciones que se producen en su interior. Es indiscutible la importancia del género que adquiere un factor que condiciona, de forma indiscutible, la distribución y organización de estos espacios.

Como colofón de este trabajo, se incluye un anexo documental que no tiene desperdicio y que está compuesto por una presentación donde trata algunos inmuebles del Cabildo catedralicio malagueño; el estudio del quaderno de medidas y, linderos, casas y huertas de los ilustres senores Dean y Cabildo de Malaga y una transcripcion de este.

Es indudable la utilidad de esta obra para el profesional interesado no solo en obtener información sino en lograr la adecuada comprensión del interior, de la vivienda desde, una vertiente que la contempla como una unidad externa e interna, aś como el valor simbólico que le aporta la materialidad y los artefactos que la hacen habitable. De este modo, se tiende la mano a investigadores a través de esta obra abriendo nuevas líneas de trabajo. La excelente argumentacion y perfecta conjugación entre lo teorico y lo practico no defraudara ni al lector mas avezado en la materia. 